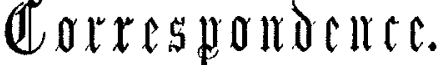

"Audi alteram partem."

\section{CERTIFICATION OF THE CAUSE OF DEATH.}

To the Editor of The LANCET.

SIR,-In THE LANCET of March 18th reference is made to the views of a coroner's clerk who said that a doctor should give a certificate of the cause of death although the doctor had not seen the deceased for six months before death. Those interested in this question should read the recommendations of the Select Committee on Death Certification of the House of Commons (1893). This Select Committee reported as follows :-

Your Committee consider that attendance "during last illness" should be defined as meaning personal attendance by the person certifying upon at least two occasions, one of which should be within eight days of death.

The Committee also recommended that before giving a certificate the doctor should be required personally to inspect the dead body, and so verify not only the cause of death, but also the fact of death.

Some practitioners carry out these recommendations, charging a fee for the inspection and a fee for the certificate. I would suggest that practitioners obtain this Parliamentary Report with the Minutes of Evidence from Eyre and Spottiswoode, Harding-street, London, E.C., and that we all put these recommendations of the Select Committee into practical operation.

The Minutes contain my evidence relating to the above subject, and also to the custom in foreign countries relating to registration of stillborn children. The evidence led to the passing of the Notification of Births Act, 1907 and 1915. I may add that these Acts contain a very great flaw in that they provide that stillbirths under seven months shall not be notified-as if anyone can tell whether a conception is 20 or 30 weeks intra. uterine life!

Would it not give good results if the RegistrarGenerals of England, Scotland, and Ireland, in combination with the three Local Government Boards, adopted standing regulations bearing upon certification of deaths? Why "wait and see"?

I am, Sir, yours faithfully,

Liverpool. March 21st, 1916.

ROBERT R. RENTOUL.

The coroner's clerk, as we have already said, was mistaken wholly._ED. L.

\section{ALBUMINURIC RETINITIS}

To the Editor of THE LANCET.

SIR,-I warmly welcome Mr. R. Foster Moore's reply in your issue of March 4th to my note on this subject, as he accepts the differentiation of the two forms of albuminuric retinitis which $I$ have described and called the degenerative and the exsudative form. He not only accepts it, but states that he believes it to be of great importance. I wish he had gone a little further and said that it was a distinction which was fundamental. regards the exsudative form and its resemblance to that sometimes seen in cerebral tumour, I did not intend to imply, nor do I think, that it is similar to the optic neuritis commonly seen with cerebral tumour, for as a rule the exsudation forms more or less extensive areas with soft edges and of a yellowish-white colour, widely and irregularly dispersed over the fundus; but this may occur sometimes in cerebral tumour, and then the resemblance is so close that $I$ have on several occasions seen the diagnosis confused. As regards the degenerative form, Mr. Moore states that though highly characteristic it is not pathognomonic. A universal statement can hardly ever be made about anything in medicine, but I can only say that it is pathognomonic so far as my experience goes, and that I have never seen it under any other condition than granular kidney. If not abso. lutely pathognomonic it may safely be regarded as practically so. There are cases met with now and then in which tiny patches of exsudation show a very bright glistening appearance, and these, of course, may disappear if the patient gets well; but the typical glistening white patches I have not myself seen to vanish, even when they have been quite tiny-I presume because the disease upon which they depend is progressive and not curable. Mr. Moore says I did not "define" granular kidney. I hardly thought it necessary. My object was to make distinctions, not definitions, and to show how necessary it was not to use so indefinite a term as "chronic nephritis," which includes two conditions at least which should be sharply distinguishedviz., the chronic or long-standing parenchymatous nephritis giving rise to the large white kidney, and the chronic degenerative disease of very long dura. tion and of slow progress called granular kidney. The distinction is essential, because the two forms of albuminuric retinitis stand in a different relation to these two forms of chronic nephritis.

My own conclusions are based upon long clinical observation and I state them as such. I cannot doubt that the experience of others who approach the subject with an open mind will tally with my own.

I am, Sir, yours faithfully,

Wimpole-street. W., March 16th. 1916. SAMUEL WEST.

\section{THE SIGNIFICANCE OF CERVICAI CAPILLARY MARKINGS.}

To the Editor of TH E L A NCET.

SIR,-In reference to cutaneous telangiectases about the upper dorsal vertebral spines, a subject introduced by Dr. Crawshaw Holt in your issue of March 4th under the above heading, I should like to express my agreement with Dr. Parkes Weber's remarks in your issue of March 11th as to their common occurrence in healthy people; he places the incidence among healthy young adults at 50 per cent. Some time ago I examined 164 school children in a healthy London suburb in regard to the occurrence of these dilated venules with the following result. Of the 164 children 21 were aged 8 and the remainder 12 or 13 years; the incidence of spinal venules was found to be identical in the two age-groups.

They were present altogther in 71 , or 43.3 per cent.; in 16 cases they were noted as strongly marked, in 30 as slight, and in the remainder as merely "present." They extended in most cases round the spines of the seventh cervical and first or second dorsal vertebræ, but in a good number reached as low as the third to fifth spine. In 4 cases similar telangiectases occurred in abundance over the back, shoulders, arms, and chest, and in 3 over the cheeks. The chest veins were unduly visible in 20 cases ( 28 per cent.). In 5 cases $(7$ per cent.) of the 71 there was found right-sided paravertebral dullness suggestive of glandular enlarge ment (bifurcation glands). The children were for the most part well nourished, 74 per cent. in this group being classed as "good." Among the 93 cases 
(56.7 per cent.) where spinal venules were absent 71 per cent. were noted as of "good" nutrition. Only 9 cases $(9.6$ per cent.) showed dilated chest veins, and in 3 ( 3 per cent.) paravertebral dullness pointed to enlarged glands.

The higher incidence of dilated chest veins and paravertebral dullness in the first group suggests a connexion between the spinal telangiectases and enlargement of intrathoracic glands, and hence tuberculosis. In an investigation recently made by myself into the incidence and characteristics of manifest tuberculosis among children from tuberculous households it was found that $41^{\prime} 7$ per cent. (among 24 children) showed these spinal venules, while they were present in only 23 per cent. of children (22 in number) drawn from healthy house. holds in the same neighbourhood. Among the whole the incidence of venules where manifest signs of disease (mostly glandular) were present was just twice that among those with apparently normal chests. Here, again, there is evidence to suggest that the dilated spinal venules are, like dilated veins over the chest, in many cases at least, of pressure origin, and owe their presence, as was suggested by W. Overend as long ago as 1901, to pressure on right or left superior intercostal vein, or on the vena azygos major into which the former opens. Their special association with enlargement of tracheo-bronchial glands might thus be expected; but, curiously enough, where signs of this occurred among the subjects of my investigation mentioned above, the spinal venules were more often absent than present (in 8 among 10). In some cases, and notably where, as in four cases referred to, similar telangiectases are also present over other parts of the body, they are very probably of nævoid nature and allied to the venules so often present in the red parts of the cheek.

As to the value of the spinal venules in diagnosis, this may be readily gauged from their presence in over 40 per cent. of healthy young people. Even if it must be admitted, as it readily would be by myself, that the 40 per cent. were probably tuberculous, this knowledge would still avail us but little. since in civilised communities our diagnosis is not required to discriminate as a rule between the tubercle-free and the tuberculous, but between the tuberculous "healthy" and the tuberculous "diseased."

I am, Sir, yours faithfully,

Queen Anne-street, W., March 18th, 1916. CLrve RIviere.

\section{THYMO-BENZENE IN BILHARZIOSIS.}

To the Editor of THE LANCET.

SIR,-Mr. J. F. Briscoe's letter in THE LANCET of Jan. 15th on bilharziosis induces me to refer to the invariably good results of the treatment of this infection with thymo-benzene in doses of $2 \mathrm{gr}$. of the former and $3 \mathrm{ss}$ of the benzene. The thymol dissolves freely in the benzene. Given in such doses on the third day the ova are found in shoals on the slides, the majority being black. This is brought about, I suppose, by the benzene invalidating the outer envelope of the ovum and allowing blood pigments to colour the contents, miracidium, \&c. In very nearly the same time and with continuation of the drugs all the subjective and objective sym. ptoms abate. Sleep is restored, pain diminishes, and the patient rests quietly in bed at night. Giddiness is no longer complained of. The urine soon loses all appearance of blood, becomes normal in colour, with disappearance of sediment and albumin. The anæmia soon disappears, and with returning appetite strength and weight improve.
Mild cases in robust subjects lose all trace of the infection in a few weeks, no ova being found in the urine after repeated examination. In graver cases in depraved constitutions the result is not so good, but even here the patient loses all his symptoms with the exception of a few ova in the urine.

I have supposed that in the one case the worms have been in some way invalidated, toxins have evidently been rendered harmless, while secondary infections have been quite abolished. I know of no other remedy that can effect such results in this infection. It is not poisonous, and the doses above referred to have in no case given the slightest discomfort.-I am, Sir, yours faithfully, St. Mark's, Cape Province, South Africa. Wir. ROBERTSON.

\section{THE TREATMENT OF HAMORRHOIDS BY INJECTION.}

To the Editor of THE LANCET.

SIR,-A simple story is recalled to my mind by $\mathrm{Mr}$. A. S. Morley's able summary of the pros and cons of the injection treatment of hæmorrhoids in your last issue.

There was once a king in Erewhon who, like many a rich layman since his day, thought to ensure his bodily health by having a variety of medical advice. So he attached to his court two alchemists (or, as some say, phy. sicians). Their names were Bubble and Squeak, and there was great rivalry between them.

Now, in the course of his researches Bubble discovered a herb with which he claimed he could cure the fundamental ailments of the human body. (Bubble was the first proctologist in history.) Squeak said that Bubble was a quack and that the herb was not only useless but also dangerous.

One day the king's wife developed a small pile. She consulted Bubble and he cured her. So the king, who was a just king, cut off Squeak's head because he was a liar. And later on the king himself developed a pile, but a large and troublesome one, which prolapsed and was irreducible if he became excited, as kings do. He too tried Bubble's remedy, but it failed. So the king, who was a just king, cut off Bubble's head. because he was a liar.

The herb, though for all we know it had its uses, fell into disrepute. This was the result of the exaggeration of the enthusiast on the one hand and the bigotry of the sceptic on the other.

I have attempted elsewhere ${ }^{1}$ to state the situa. tion precisely. The truth is that the injection treat. ment is not quackery, as some have alleged, nor is it infallible, as others would have one believe; but that in properly selected cases it will often effect a cure and thus avoid an operation, to the great gratification of the patient.

$$
\text { I am, Sir, yours faithfully, }
$$

Queen Anne-street, W.. March 20th, $1916 . \quad$ IVOR BACK.

\section{SHELL SHOCK.}

\section{To the Editor of THE LANCET.}

SIR,-Lieutenant-Colonel Charles S. Myers in his communication on shell shock in THE LANCET of March 18th quotes two cases which illustrate a principle the application of which has receired but little attention in connexion with the war. Cases 10 and 11 are the only two in which he records the visual acuity. In both cases the unilateral symptoms mentioned are on the side of the eye with the worse visual acuity; in the one case, right frontal headache, tremors of the right arm and weakened grip of the right hand, right hemianalgesia, hemianæsthesia, hemianosmia and hemiageusia, loss of stereognostic and vibra. tion sense on the right side, right nerre-deafness and limitation of the right visual field; in 